\title{
Caracterização de Mutações no Gene BRCAl em Pacientes com Câncer de Mama e ou Ovário Hereditários do Instituto Nacional de Câncer-RJ
}

\author{
Characterization of Mutations in BRCA1 Gen in Patients with inherited Breast \\ and/or Ovary Cancer in National Cancer Institute (INCA - RJ)
}

Autor: Juliano Javert Lourenço

Orientador: Dr. Miguel Angelo Martins Moreira

\section{Resumo}

Mutaçôes no gene BRCA1 são conhecidas como a causa mais freqüente a predisposição aos cânceres hereditários de mama e ovário. Embora menos que $10 \%$ de todos os casos de câncer de mama e ovário manifestem características hereditárias, estima-se que até $80 \%$ dos casos hereditários são relacionados a mutações no gene BRCA1. A maioria das mulheres com câncer de aparecimento precoce e forte história familiar são portadoras de mutações em BRCA1. A identificação e caracterização destas mutações na população brasileira são cruciais para o aconselhamento genético e prevenção. Neste trabalho, apresentamos dados da seqüência de ADN de 47 pacientes que foram selecionados pelo Grupo de Aconselhamento Genético em Câncer de Mama e Ovário do Instituto Nacional de Câncer-RJ. Todos os éxons codificantes e junções íntron-éxon foram analisadas. Sete mutaçôes (15\%) foram encontradas em BRCA1 entre os 47 pacientes incluídos na investigação: uma idêntica inserção (insC 5382) foi encontrada no éxon 20 de quatro pacientes, uma deleção de quatro pares de bases (3450 del4 CAAG) no éxon 11, resultando em um códon de parada, no quinto paciente; uma transição (T>C IVS 17+2) no íntron 17, afetando o sítio de processamento do ARNm no sexto paciente; e uma transição $\mathrm{C}>\mathrm{T}$ resultante em um códon de parada (Q1135X) no éxon 11 do sétimo paciente. Outro paciente sem mutaçóes detectadas em BRCA1 apresentou uma mutação em BRCA2 (IVS $21+4 \mathrm{~A}>\mathrm{G}$ ) no íntron 21 , outro gene relacionado ao câncer de mama masculino e feminino. A identificação destas mutações associadas aos cânceres de mama e ovário hereditários contribuirá para o conhecimento do perfil mutacional de BRCA1 na população brasileira. 